\title{
Article
}

\section{Analysis of Driving Control Characteristics in Typical Road Types}

\author{
Baicang Guo (D), Qiang Hua, Lisheng Jin *, Xianyi Xie, Zhen Huo and Huanhuan Wang
}

Citation: Guo, B.; Hua, Q.; Jin, L.; Xie, X.; Huo, Z.; Wang, H. Analysis of Driving Control Characteristics in Typical Road Types. Sustainability 2022, 14, 782. https://doi.org/ $10.3390 /$ su14020782

Academic Editors: Xiaobei Jiang, Haixiang Lin, Fei Yan and Qian Cheng

Received: 19 October 2021 Accepted: 4 January 2022 Published: 11 January 2022

Publisher's Note: MDPI stays neutral with regard to jurisdictional claims in published maps and institutional affiliations.

Copyright: (c) 2022 by the authors. Licensee MDPI, Basel, Switzerland. This article is an open access article distributed under the terms and conditions of the Creative Commons Attribution (CC BY) license (https:// creativecommons.org/licenses/by/ $4.0 /)$.

\author{
School of Vehicle and Energy, Yanshan University, Qinhuangdao 066004, China; guobaicang@ysu.edu.cn (B.G.); \\ huaqiang_lyf@163.com (Q.H.); xiexianyi123@126.com (X.X.); vehicle_huo@126.com (Z.H.); \\ wanghuanhuan_ysu@126.com (H.W.) \\ * Correspondence: jinls@ysu.edu.cn
}

\begin{abstract}
Vehicle control requirements for longitudinal and lateral driver control are varied in different road geometries; this makes it irrational and superfluous to represent driving control characteristics with repetitive indices. To address this problem, the present study used multiple crossanalysis methods of vehicle running state parameters from experienced drivers in order to deeply study driving control characteristics in different road geometries. Six common road geometries with different driving control emphases were selected as typical road types and twenty-five experienced drivers were asked to perform an actual driving test. Taking the indices in the long straight road as the control variable, the indices in other roads were compared with it and judged according to the three methods: the overall distribution by box plots, significant difference test by analysis of variance (ANOVA) and relative distance calculation by technique for order preference by similarity to an ideal solution (TOPSIS). Moreover, the weight of the driving control characteristic index was calculated through the entropy weight method to reflect its importance. In this paper, the relationships between road geometry and driving control characteristics explicate the influence mechanism and interaction of road geometry on driving behavior, and the indicators that can reflect the control characteristics in different road types are obtained.
\end{abstract}

Keywords: traffic safety; human factor; driving control characteristics; vehicle running status; driving behavior; naturalistic driving data

\section{Introduction}

In the United States, horizontal curved roads appear to be among the deadliest locations, figuring in over the $50 \%$ of traffic fatalities [1]. Exploring the driver-road interactive mechanism can strengthen road design strategies to create a safer environment, because road design criteria usually do not consider driver behavior and are often based on vehicle physics and predetermined design speed [2]. It is also helpful to study the differences in driving behavior in different driving settings. The indices of driving control characteristics are the most direct quantitative variables used to reflect the running state of vehicles and human factors.

On the one hand, driving control characteristics are reflected by various vehicle running parameters, such as velocity, acceleration, yaw rate, and their derived indicators are most commonly selected. Based on the significant difference of these variables in reflecting a dangerous state, the correlations were found to be strong enough to warrant the use of acceleration behavior as a predictive variable for transportation safety research [3]. Furthermore, Simonsmorton et al. [4,5] proposed a g-force event recognition method to identify and classify risky driving events by aberrant acceleration and deceleration parameters. According to the data storage system of driving behaviors, the Greenroad company conduced a safety analysis of driver behaviors and evaluated different driving habits and safety indicators. This company has played a positive role in preventing potential traffic accidents [6]. The Volkswagen Group in Germany has established a database of drivers' handling behavior, vehicle status and environmental information. Then, the 
driver's behavior with the data was analyzed, and the driver's driving behaviors in the curves were studied [7]. Moreover, driving while fatigued can also be identified noninvasively by using steering angle, vehicle speed fluctuation and lane offset $[8,9]$. Risky vehicle running state parameters that were collected in naturalistic driving experiments were combined to judge whether the vehicle was in danger by the maximum and average values of longitudinal acceleration and lateral acceleration [10]. The standard deviation of the steering wheel angle, rotation angle of the steering wheel, braking acceleration, and emergency braking times are important parameters used to measure a driver's ability to manipulate the vehicle [11,12]. Farahmand et al. tested three different levels of curved roads by recording drivers' steering wheel movements, the standard deviation of steering wheel movements, and lane positioning ability [13].

On the other hand, sites with different road geometries have various handling difficulties. (For example, compared to long straight roads, which mainly require the longitudinal operation of driver, the continuous S-curved roads need both longitudinal and lateral handling actions.) Long straight roads and curved roads are commonly used among typical road geometries. The most representative straight road is the highway; experiments on simulated highway scenes were carried out to study driving performance when engaging in distracted behaviors [14]. Roads in transportation systems are not always straight, and actual traffic phenomena on horizontal curved roads are different from those on straight roads due to the effects of curved forces and restrictions on visibility [15]. Gu et al. [16] explored the turning speed of the whole curve by using the shape characteristics of the road. Kang et al. [17] examined how different curved roads influence concurrent-driver driving behavior and vehicle maneuvering performance along a simulated continuously curved road. Cerni et al. [18] studied the trajectory of the vehicle curve and established a trajectory model considering the geometric characteristics of the road and vehicle dynamics. In the view of $[19,20]$, a low curve radius was the riskiest deficiency related to road geometry, but lane width, shoulder width, and horizontal geometry were also proven to increase road risk rates [21,22]. Chu et al. [23] proposed an improved curve speed model considering driving styles as well as vehicle and road factors. However, Carsten et al. hold that it is not certain that the results obtained in one road type are still available in other road-alignment-based research, so that such results lack practical applications [24]. Furthermore, considering that road path information is directly contained in the vehicle running state, it is necessary to remove the road information from the vehicle driving state data before evaluating driving behaviors [25]. As an example, in a study regarding driving simulator experiments on the effects of driver distraction, the authors reported that the experiments varied considerably in terms of sample characteristics, design, and analysis methods, exposing a lack of uniformity in the way they are conceived, conducted and exploited [20].

After reviewing the literature according to the two aforementioned aspects, we can conclude that there exist three questions to be solved. Firstly, simulated driving has many advantages, such as free creation of road types, safe data acquisition experiments and an efficient research process. However, the gap with the real driving experience (speed feeling, road feedback, driving attention, etc.) is an important factor in producing unreliable analysis results. Secondly, to improve the applicability and scope of the parameters, it is necessary to develop a common indicator set that can be used in diversified road types. Thirdly, assuming that the on-board safety evaluation system will switch its corresponding characteristic parameters when driving in different road types, a weighting of the parameters is needed for model calculating.

In this paper, we emphasize the importance of establishing a differentiated and precise index set which can be used in several prevailing road geometries. The steps are the following:

(1) An experiment is designed in a closed test site to build a naturalistic dataset which contains both vehicle running state parameters collected from typical road types and interaction behaviors between vehicles. 
(2) Taking the driving control parameters in a long straight road as the control group, multiple vehicle running parameters and their derivative indices undergo a crossanalysis to show the driving control characteristics in different road types.

(3) After weighing the indices in each road types, the differentiated indices of driving control characteristics in each scene can be obtained. Finally, the results of the driving control characteristics in different road types are analyzed and discussed.

\section{Experiment and Dataset}

\subsection{Subjects}

In this paper, 25 experienced drivers with legal driving licenses were recruited as subjects to carry out a real vehicle test on a closed test ground. The age of the subjects was 29 to 36 years (mean $=31$ years), their actual driving experience was 4 to 7 years (mean $=5.3$ years), and their driving frequency in the past year was more than 15 times per month. To make the data better reflect the driving control characteristics during the driving tasks, the drivers had fully understood the process and content of the experiment so that they could better complete the expected task during the experiment. More than $10 \mathrm{~h}$ of experiments were carried out in total, and the data were collected sufficiently.

\subsection{Experiment Site}

Naturalistic driving data are an effective tool to analyze vehicle motion characteristics. They can reduce the distortion and unreal driving experience of simulated driving, especially highlighting the interaction between driver and road with good reproducibility.

An overhead view of the site is shown in Figure 1. The test ground was a two-lane road including a long straight road, roundabout, L-corner, width-limited road, continuous deceleration zone, L-corner and S-curve. The design speed of the long straight road, widthlimited road and deceleration zone were $70 \mathrm{~km} / \mathrm{h}, 50 \mathrm{~km} / \mathrm{h}$ and $20 \mathrm{~km} / \mathrm{h}$, respectively. The road width was $6 \mathrm{~m}$. The total length of the selected test section was about $3.6 \mathrm{~km}$. The experimental site was a closed area with no other moving obstacles except auxiliary vehicles, the visibility was greater than $2 \mathrm{~km}$, and the road surface was complete, clear and unobstructed. According to the planned route, each driver was supposed to drive a full circuit on the grounds (two circles in roundabout), and the scenes passed in order were: long straight 1 , roundabout, long straight 2 , L-corner, width-limited road, continuous deceleration zone, L-corner, S-curve.
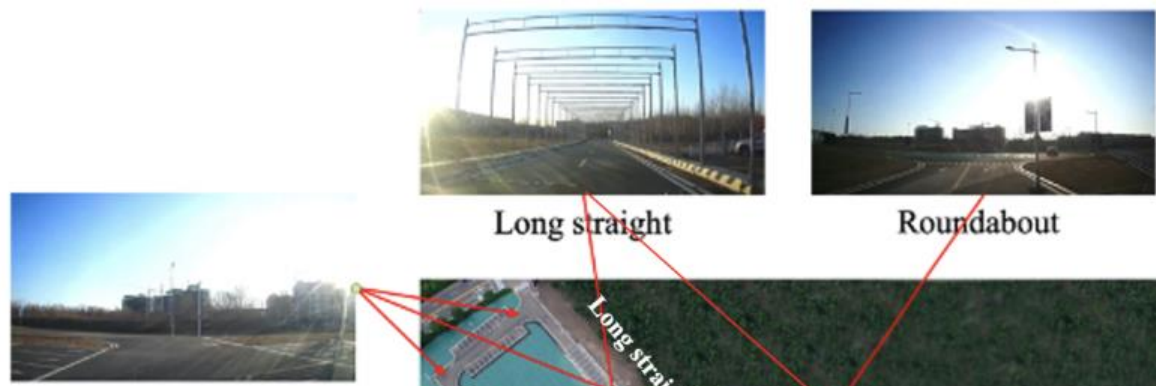

L corner
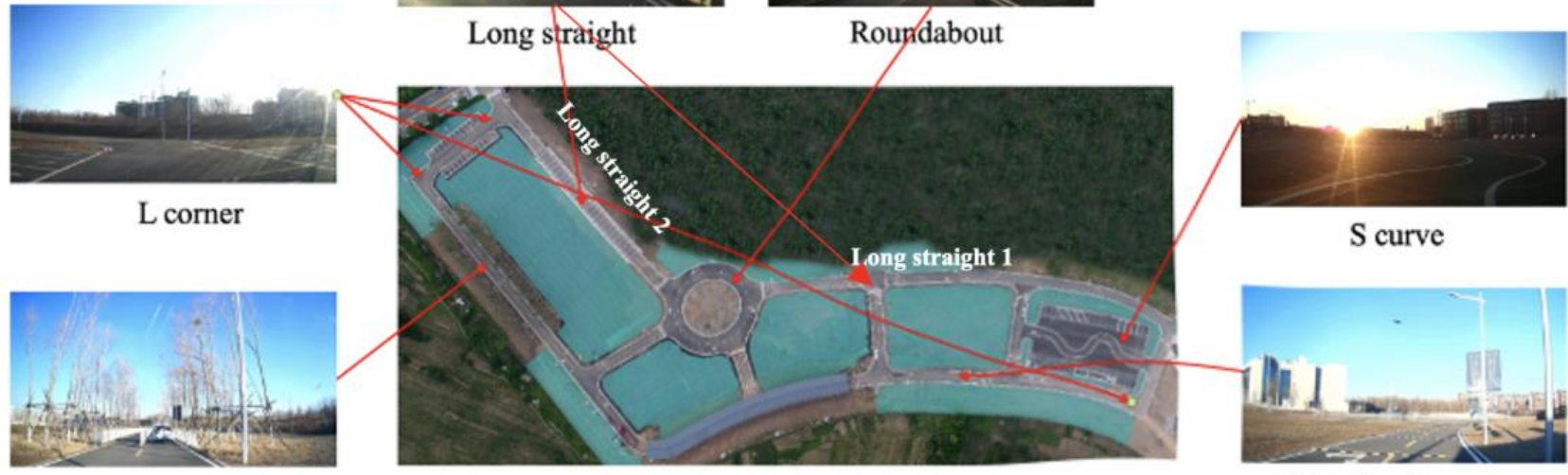

Width limited

Deceleration zone

Figure 1. Real vehicle test site and its main driving scenes. 


\subsection{Experiment Design}

Before the test, all drivers were asked to adjust the seat and rearview mirror to their customary position. A copilot was provided as an assistant responsible for explaining the test process, driving route, test scheme and speed limitation before the test, as well as for terminating an invalid test and dealing with emergency events during the test. The experiment was divided into three stages. (1) Free driving: The subjects drove unrestricted in the field until they were familiar with the road conditions. (2) Practice driving: The driving test was carried out according to the experimental scheme. No data was collected at this stage; however, the subjects became more familiar with and better understood the experimental scheme. (3) Formal experiment: In this stage, the experimental scheme was strictly implemented and the required data were collected. Because the experience was a real vehicle experiment, once equipment problems or driving errors would occur the process would be interrupted and the experiment restarted.

In the formal experiment stage, four vehicles were used in the whole test. The main vehicle was called the testing vehicle and the other vehicles were called auxiliary vehicles. In order to approximate a real road scene, a series of vehicle interaction behaviors were designed in the road section (long straight, width-limited and roundabout). The design of the interactive driving process is shown in Figure 2. Driving tasks designed in different road sections have different inspection focuses. The width-limited segment focuses on variablespeed car-following in a single lane. The roundabout segment focuses on lane changes and cut-ins in a long curve. Long straight 1 mainly focuses on passive interference suffered by other drivers and obstacles, while long straight 2 mainly investigates the driver's active performance of driving tasks. Moreover, L-corner, S-curve and deceleration zone are used respectively to investigate the control characteristics of drivers when they turn, turn continuously and decelerate, without involving the interaction with other vehicles.

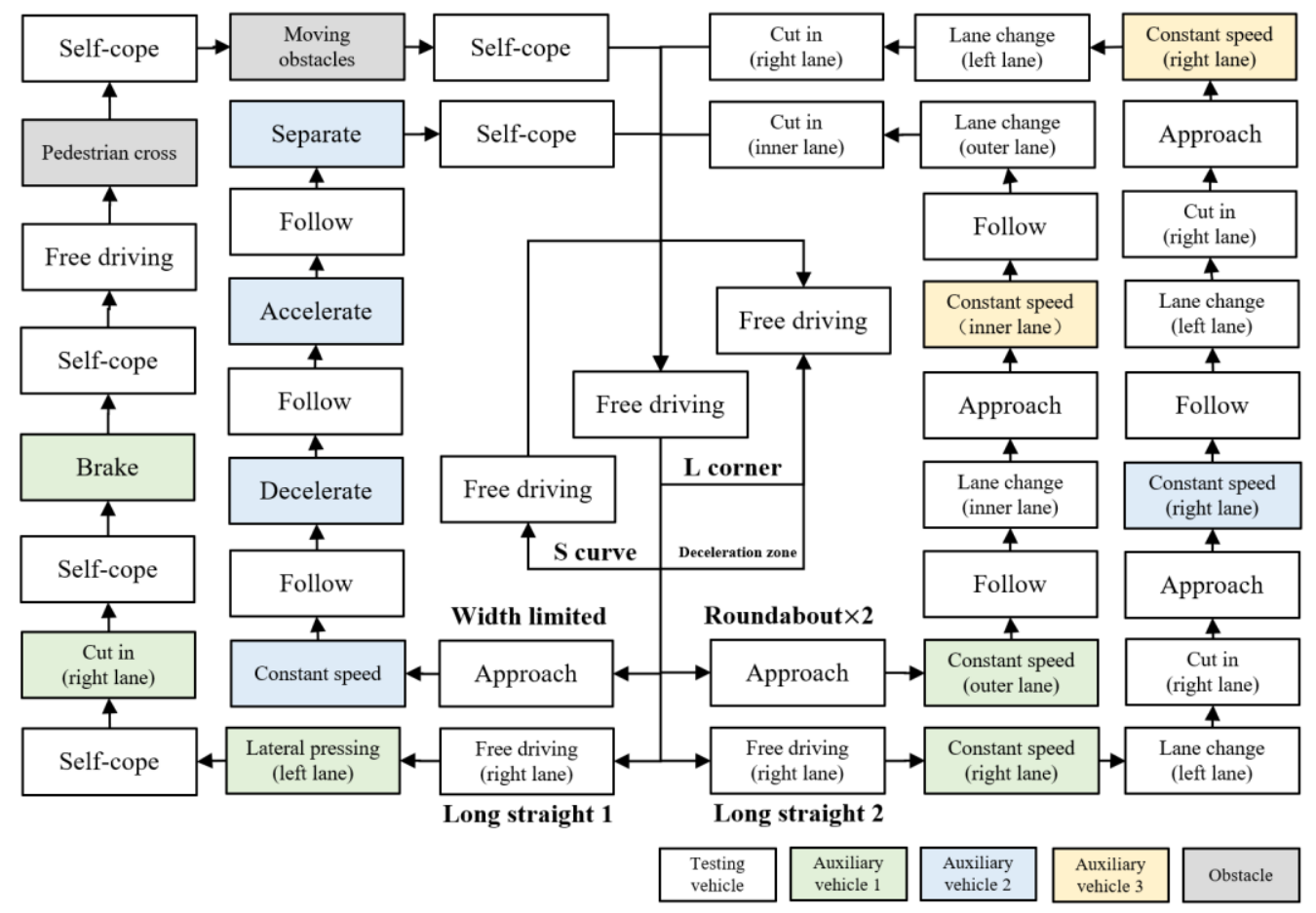

Figure 2. Vehicle interaction behaviors.

To reduce the influence of unnecessary interference factors, we implemented the following strict control measures before and during the experiment: 
(a) The driver was strictly required to follow the lane line and not to press the line. The driving task for each road segment had to be completed; otherwise, the driver was required to start again.

(b) The driver was required to pay full attention without engaging in any secondary tasks, such as talking or making phone calls. No drug or alcohol effects were observed.

(c) Each time the experiment was repeated, the starting and ending points of the vehicle had to correspond to the setting lines strictly.

\subsection{Establishment of Dataset}

During the test, the vehicle running parameter data, an 1080p HD video in the front of the car, driving position video and in-vehicle recordings were recorded simultaneously. The driving position video and in-vehicle recording were used as the assistant reference when processing the data. Two time axes were respectively established for the vehicle running parameters and the road video ahead. After overlapping the two time axes, the vehicle running parameter data corresponding to the scene in the same time period were captured and marked. Then, the vehicle manipulation dataset of different drivers in each scene was obtained. To unify the data interception standards of each scene when using the time axis to cut out the data for the vehicle running parameters, the starting node was the time when the vehicle head entered the starting line, and the terminal node was the time when the vehicle body completely passed through the driving out line. The process of establishing the dataset is shown in Figure 3. Finally, the abnormal values of the parameters were eliminated by using the Pauta criterion.

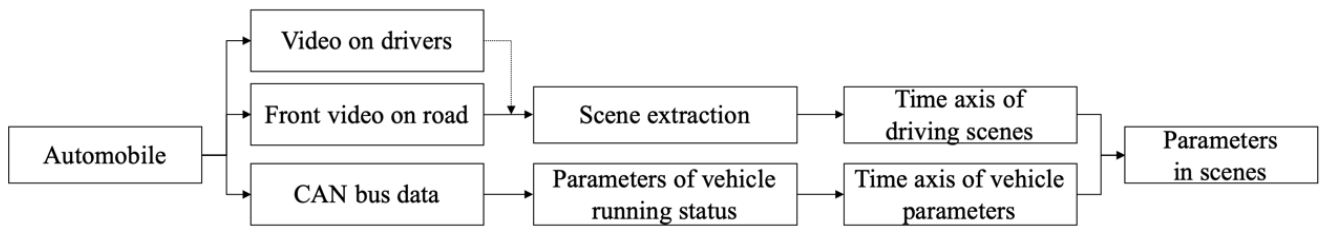

Figure 3. Process of establishing the dataset.

The vehicle control ability was mainly reflected in two aspects: longitudinal control and lateral control, which were utilized to study the driving control characteristics in different driving scenes in the present research. To obtain a comprehensive set of indices to better reflect the characteristics, the mean and the standard deviation of the original variables were added as the derived variables. In this paper, eighteen driving control characteristic parameters were selected, as shown in Table 1. The main six indices were directly collected from the CAN data and the other derived parameters were the mean or standard deviation of the abovementioned indices. The description of the parameters is listed below:

(a) Longitudinal velocity (LOV): Velocity in the direction of the vehicle.

(b) Longitudinal acceleration (LOA): Acceleration in the direction of the vehicle.

(c) Braking force $(\mathrm{BF})$ : Real-time pressure value of the brake pedal.

(d) Yaw rate (YR): The deflection of a car about the vertical axis.

(e) Steering wheel angle velocity (SWV): Ratio of steering wheel angle difference to sampling time interval between adjacent sampling points.

(f) Lateral acceleration (LAA): Acceleration perpendicular to the direction of the car.

Drawing on the hypothetico-deductive method [26-29] based on automobile theory, we assumed that the drivers could reflect the differences in driving control characteristics in the corresponding scenes. Finally, the hypothesis was verified through the analysis of the real vehicle running data, with those in line with the hypothesis being used as the characteristic parameters. 
Table 1. Hypothetical characteristic parameters of vehicle operation state.

\begin{tabular}{ccc}
\hline Vehicle Running State & Hypothetical Characteristic Parameters & Abbreviation \\
\hline & Longitudinal velocity & LOV \\
& Mean of longitudinal velocity & M-LOV \\
& Standard deviation of longitudinal velocity & SD-LOV \\
Longitudinal acceleration & LOA \\
& Mean of longitudinal acceleration & M-LOA \\
& Standard deviation of longitudinal acceleration & SD-LOA \\
& Braking force & BF \\
Mean of braking force & M-BF \\
& Standard deviation of braking force & SD-BF \\
\hline Lateral direction & Mean of yaw rate & YR \\
& M-YR \\
& Standard deviation of yaw rate & SD-YR \\
& Steering wheel angle velocity & M-SWV \\
Mean of steering wheel angle velocity & SD-SWV \\
Standard deviation of steering wheel angle & velocity & LAA \\
& Lateral acceleration & M-LAA \\
& Mean of lateral acceleration & SD-LAA \\
\hline
\end{tabular}

\section{Driving Control Characteristic Evaluation Indices}

\subsection{Entropy Weight Method}

Entropy was first derived in physics and later developed into a common method in multi-objective decision-making and evaluation $[30,31]$. In the present study, the entropy weights have two roles: one is to directly reflect the weight of each index, and the other is to calculate the distance between indexes in a TOPSIS analysis. After establishing the dataset for the vehicle running status in the driving scenes, the entropy weights of the indices were calculated. The entropy method can avoid the errors caused by the difference between the indices and can objectively show the hidden information in the data. The higher the entropy weight is, the more important the index is. The calculation steps are as follows.

Step 1. Standardized evaluation matrix.

$$
\begin{aligned}
X & =\left(\begin{array}{ccc}
x_{11} & \cdots & x_{1 n} \\
\vdots & \ddots & \vdots \\
x_{m 1} & \cdots & x_{m n}
\end{array}\right) \\
x_{i j}^{\prime} & =\frac{\left|x_{i j}-\min \left\{x_{j}\right\}\right|}{\max \left\{x_{j}\right\}-\min \left\{x_{j}\right\}}
\end{aligned}
$$

where $X$ is the matrix of the original data, $\mathrm{m}$ is the length of the indices and $\mathrm{n}$ is the number of indices. $x_{i j}$ is the original data and $x_{i j}^{\prime}$ is the standardized data.

Step 2. Characteristic proportion of indices.

$$
p_{i j}=\frac{x_{i j}^{\prime}}{\sum_{i=1}^{m} x_{i j}^{\prime}}
$$

Step 3. Information entropy of the indices.

$$
e_{j}=-k \sum_{i=1}^{m} p_{i j} \ln \left(p_{i j}\right)
$$

where $k=\frac{1}{\ln (m)}, p_{i j}$ is the characteristic proportion of the indices, and ej is the information entropy of the indices.

Step 4. Weight calculation based on information entropy redundancy. 


$$
w_{j}=1-\frac{e_{j}}{\sum_{j=1}^{n}\left(1-e_{j}\right)}
$$

where $w_{j}$ is the weight value of the driving control evaluation index.

\subsection{Technique for Order Preference by Similarity to an Ideal Solution}

TOPSIS is a sort method based on the close degree of limited evaluation objects and idealized objectives. It uses a distance metric to measure the sample gap. In this paper, the distance between other scene indices and the benchmark (long straight) is calculated. In order to avoid the scale confusion caused by the disunity of the index dimensions and to ensure the benchmark as the center, the intermediate indicator processing method was used to process the indicators in a positive way. Based on the entropy weight results, the proximity between each index and long straight scene index was calculated. The farther the distance is, the greater the deviation between the indices [24-27].

Step 1. The intermediate positive processing of indices

$$
\begin{gathered}
\tilde{x}_{i j}=1-\frac{\left|x_{i j}-x_{L}\right|}{\max \left\{\left|x_{i j}-x_{L}\right|\right\}} \\
\tilde{X}=\left\{\tilde{x}_{i j}\right\}
\end{gathered}
$$

where $x_{i j}$ is raw data, $\tilde{x}_{i j}$ is the data after intermediate positive processing. In this paper, the index in the long straight scene is taken as the control variable, so that $x_{L}$ is the index value in the scene.

Step 2. Construction of normalized initial matrix

$$
\begin{gathered}
z_{i j}=\frac{\left|\tilde{x}_{i j}\right|}{\sqrt{\sum_{i=1}^{n} \tilde{x}_{i j}^{2}}} \\
Z=\left[\begin{array}{ccc}
z_{11} & \cdots & z_{1 m} \\
\vdots & \ddots & \vdots \\
z_{n 1} & \cdots & z_{n m}
\end{array}\right]
\end{gathered}
$$

where $z_{i j}$ is the normalized value of the vector for the positive index, that is, each column element is divided by the norm of the current column vector. $Z$ is the normalized initial matrix.

Step 3. Distance calculation between indices in other scenes and the long straight scene.

$$
\begin{gathered}
Z^{+}=\left(Z_{1}^{+}, Z_{2}^{+}, \cdots Z_{m}^{+}\right) \\
=\left(\max \left\{z_{11}, z_{21}, \cdots, z_{n 1}\right\}, \max \left\{z_{12}, z_{22}, \cdots, z_{n 2}\right\}, \cdots, \max \left\{z_{1 m}, z_{2 m}, \cdots, z_{n m}\right\}\right) \\
D_{i}^{+}=\sqrt{\sum_{j=1}^{m} w_{j}\left(Z_{j}^{+}-z_{i j}\right)^{2}}
\end{gathered}
$$

where $w_{j}$ is the weight value calculated by Equation (5). $D_{i}^{+}$is the distance between indices in other scenes and the long straight scene.

\subsection{Weight and Distance Calculation of Characteristic Evaluation Indices in Typical Road Types}

After the calculation by the entropy weight method, the weight values of the driving control characteristic evaluation indices in different road types were listed in Table 2. Entropy is an important scale for measuring amounts of information. The larger the value of the entropy weight, the larger the amount of information carried by the index and the more it can reflect the change rule of the driving control behavior in the corresponding scene. Based on this, the distances between indices in other scenes and long straight scenes 
were obtained. Taking the indices in long straight scenes as the center, the radar chart is drawn in Figure 4.

Table 2. Entropy weights of characteristic evaluation indices in different road types.

\begin{tabular}{|c|c|c|c|c|c|c|}
\hline Evaluation Index & Roundabout & Long Straight & L-Corner & Width-Limited & Deceleration Zone & S-Curve \\
\hline LOV & 0.206 & 0.140 & 0.220 & 0.161 & 0.153 & 0.120 \\
\hline M-LOV & 0.255 & 0.146 & 0.231 & 0.113 & 0.085 & 0.169 \\
\hline SD-LOV & 0.206 & 0.205 & 0.129 & 0.180 & 0.136 & 0.144 \\
\hline LOA & 0.347 & 0.073 & 0.032 & 0.017 & 0.039 & 0.493 \\
\hline M-LOA & 0.339 & 0.272 & 0.081 & 0.079 & 0.094 & 0.134 \\
\hline SD-LOA & 0.174 & 0.251 & 0.146 & 0.198 & 0.117 & 0.115 \\
\hline $\mathrm{BF}$ & 0.181 & 0.204 & 0.064 & 0.291 & 0.182 & 0.078 \\
\hline $\mathrm{M}-\mathrm{BF}$ & 0.244 & 0.145 & 0.189 & 0.096 & 0.194 & 0.133 \\
\hline SD-BF & 0.226 & 0.126 & 0.176 & 0.141 & 0.202 & 0.129 \\
\hline YR & 0.154 & 0.171 & 0.182 & 0.168 & 0.166 & 0.159 \\
\hline M-YR & 0.142 & 0.159 & 0.154 & 0.244 & 0.151 & 0.150 \\
\hline SD-YR & 0.197 & 0.222 & 0.134 & 0.213 & 0.103 & 0.131 \\
\hline SWV & 0.260 & 0.040 & 0.080 & 0.170 & 0.150 & 0.290 \\
\hline M-SWV & 0.130 & 0.050 & 0.36 & 0.08 & 0.150 & 0.230 \\
\hline SD-SWV & 0.110 & 0.246 & 0.231 & 0.140 & 0.150 & 0.123 \\
\hline LAA & 0.163 & 0.167 & 0.325 & 0.156 & 0.049 & 0.139 \\
\hline M-LAA & 0.201 & 0.255 & 0.177 & 0.158 & 0.110 & 0.100 \\
\hline SD-LAA & 0.224 & 0.195 & 0.175 & 0.127 & 0.106 & 0.173 \\
\hline
\end{tabular}

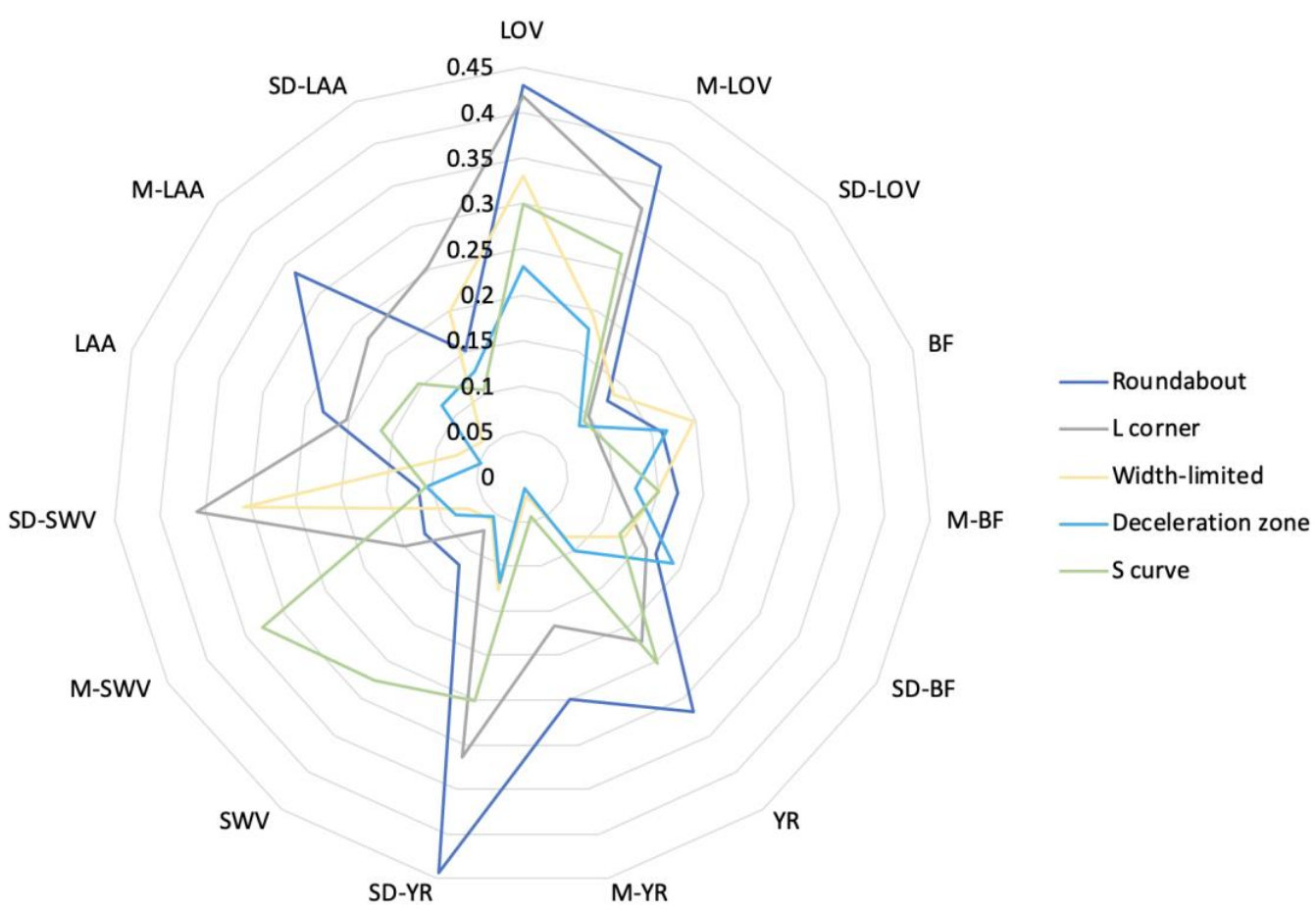

Figure 4. The distance between indices in in long straight scenes and other scenes.

\subsection{Longitudinal Parameters}

3.4.1. Longitudinal Velocity

(a) From the box plot (Figure 5), the distribution of LOV values in each scene is different. 


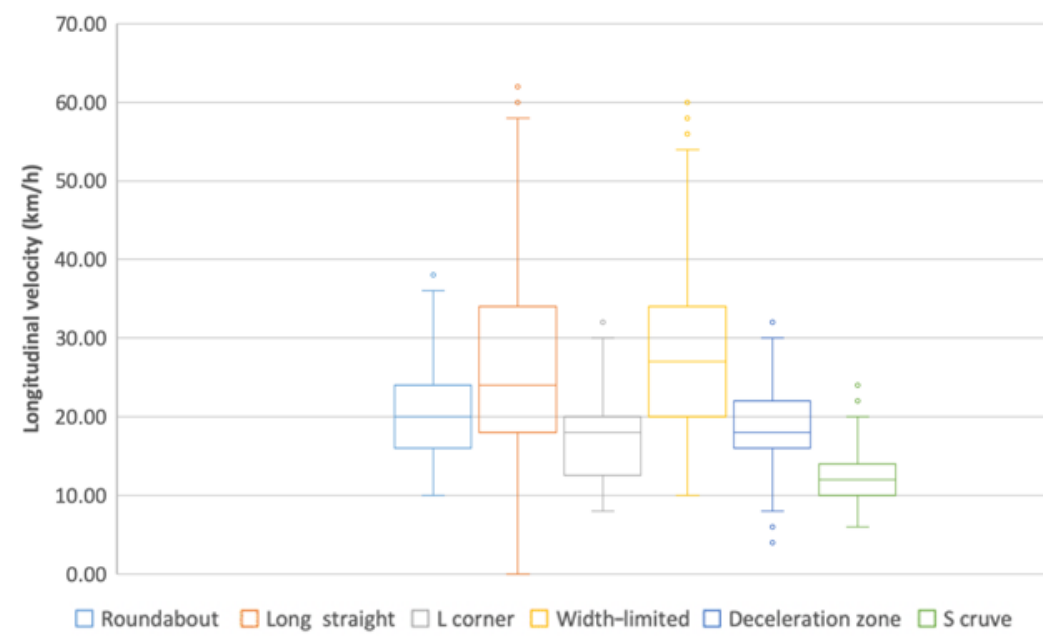

Figure 5. Distribution of LOV values in different scenes.

(b) From the radar chart (Figure 4), the LOV in other scenes is far away from that in the long straight scene, and there is no close coincidence among them. This is in line with the result of (a).

(c) From the ANOVA (Table 3), it can be seen that in different scenes, the difference of LOV in every scene is extremely significant, which is in line with the result of (a) and (b).

Table 3. Significant comparison results of LOV in different scenes.

\begin{tabular}{cccc}
\hline \multicolumn{2}{c}{ Driving Scenes } & Mean Difference & Sig. \\
\hline & Roundabout & $4.904^{*}$ & 0.000 \\
L-corner & $7.276^{*}$ & 0.000 \\
Long straight & Width-limited & $-2.838^{*}$ & 0.000 \\
& Deceleration & $6.108^{*}$ & 0.000 \\
& S-curve & $11.885^{*}$ & 0.000 \\
\hline
\end{tabular}

* The mean difference is significant at the 0.05 level.

(d) Summary: LOV shows significant differences in each scene and can be used to represent the driving control characteristics in six scenes.

3.4.2. Mean of Longitudinal Velocity

(a) From the box plot (Figure 6), the distribution of M-LOV values in each scene is different.

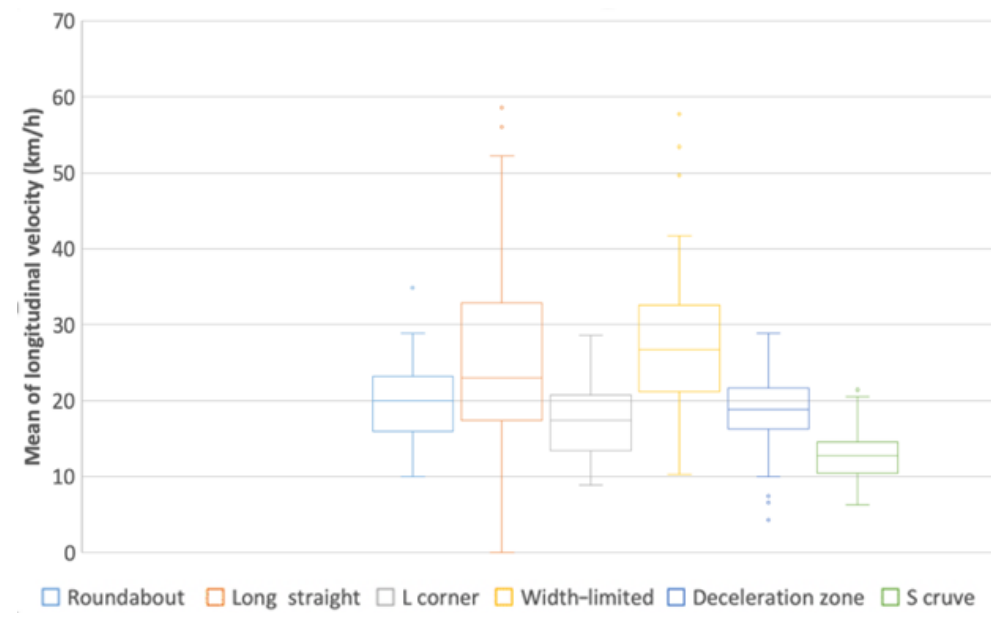

Figure 6. Distribution of M-LOV values in different scenes. 
(b) From the radar chart (Figure 4), the M-LOV values in other scenes are far away from that in the long straight scene. This is in line with the result of (a).

(c) From the ANOVA (Table 4), it can be seen that in different scenes, the differences of LOV in every scene are extremely significant, which is in line with the result of (a) and (b).

Table 4. Significant comparison results of M-LOV in different scenes.

\begin{tabular}{|c|c|c|c|}
\hline \multicolumn{2}{|c|}{ Driving Scenes } & \multirow{2}{*}{$\begin{array}{c}\text { Mean Difference } \\
4.904^{*}\end{array}$} & \multirow{2}{*}{$\begin{array}{c}\text { Sig. } \\
0.000\end{array}$} \\
\hline \multirow{5}{*}{ Long straight } & Roundabout & & \\
\hline & L-corner & $7.273 *$ & 0.000 \\
\hline & Width-limited & $-2.850 *$ & 0.006 \\
\hline & Deceleration & $6.206 *$ & 0.000 \\
\hline & S-curve & $11.885 *$ & 0.000 \\
\hline
\end{tabular}

* The mean difference is significant at the 0.05 level.

(d) Summary: M-LOV shows significant differences in each scene and can be used to represent the driving control characteristics in six scenes.

\subsubsection{Standard Deviation of Longitudinal Velocity}

(a) From the box plot (Figure 7), the distribution of SD-LOV values in width-limited and deceleration scenes are similar, and the rest are different from each other.

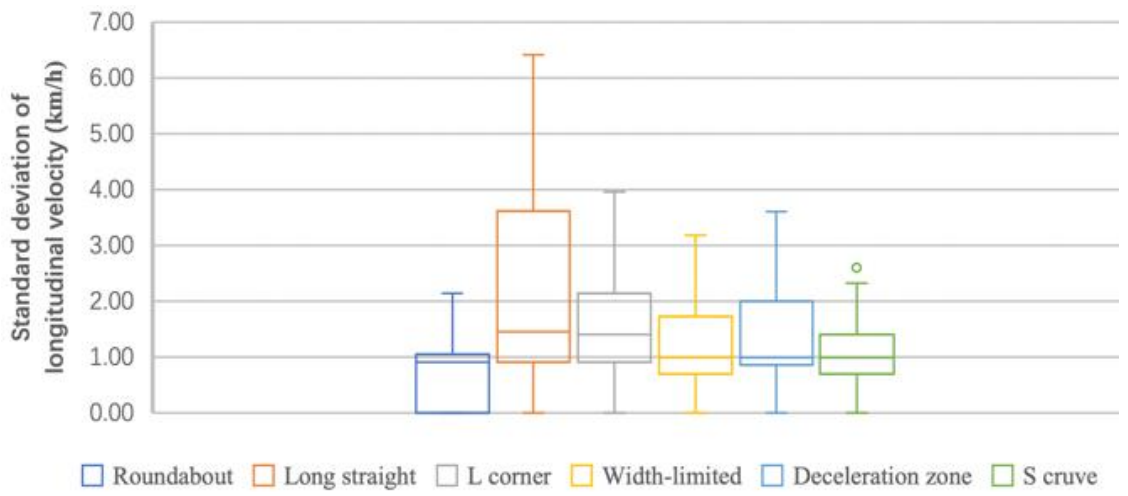

Figure 7. Distribution of SD-LOV values in different scenes.

(b) From the radar chart (Figure 4), the SD-LOV values in other scenes are far away from that in the long straight scene.

(c) From the ANOVA (Table 5), it can be seen that in different scenes, the differences of SD-LOV in every scene are extremely significant, which is in line with the result of (a) and (b).

Table 5. Significant comparison results of SD-LOV in different scenes.

\begin{tabular}{cccc}
\hline \multicolumn{2}{c}{ Driving Scenes } & Mean Difference & Sig. \\
\hline & Roundabout & $1.629 *$ & 0.000 \\
L-corner & $0.779 *$ & 0.001 \\
Long straight & Width-limited & $1.027^{*}$ & 0.000 \\
& Deceleration & $0.985^{*}$ & 0.002 \\
& S-curve & $1.635^{*}$ & 0.000 \\
\hline
\end{tabular}

* The mean difference is significant at the 0.05 level.

(d) Summary: The results of (a), (b) and (c) cannot be consistent; thus, the SD-LOV does not meet the requirements. 


\subsubsection{Braking Force}

(a) From the box plot (Figure 8), the distribution of BF values is analogous between roundabout and L-corner, S-curve and width-limited.

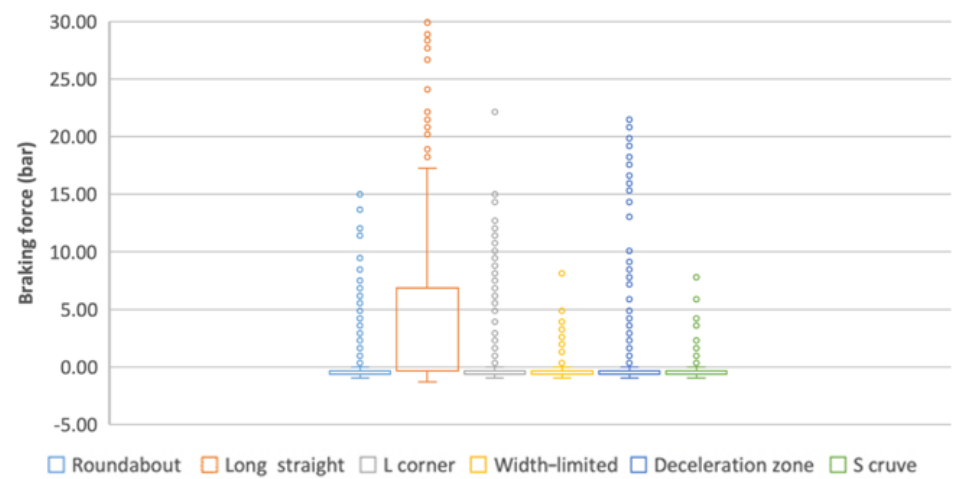

Figure 8. Distribution of BF values in different scenes.

(b) From the radar chart (Figure 4), the BF values in other scenes are far away from that in the long straight scene, which in line with (c). However, roundabout and deceleration zone, as well as L-corner and S-curve, almost coincide.

(c) From the ANOVA (Table 6), there are significant differences in BF between other scenes and the long straight scene.

Table 6. Significant comparison results of BF in different scenes.

\begin{tabular}{cccc}
\hline \multicolumn{2}{c}{ Driving Scenes } & Mean Difference & Sig. \\
\hline & Roundabout & $4.098^{*}$ & 0.000 \\
L-corner & $3.583^{*}$ & 0.000 \\
Long straight & Width-limited & $4.301 *$ & 0.000 \\
& Deceleration & $3.019 *$ & 0.000 \\
& S-curve & $4.222^{*}$ & 0.000 \\
\hline
\end{tabular}

* The mean difference is significant at the 0.05 level.

(d) Summary: Although (b) and (c) reflect the coincident differences among indices, the results of (a) and (b) indicate that there may be multiple collinearity problems between each index, so that BF cannot be used to represent the respective characteristics of scene indices.

\subsubsection{Mean of Braking Force}

(a) From the box plot (Figure 9), the distribution of M-BF values is analogous between width-limited and S-curve, while the distribution of others is varied.

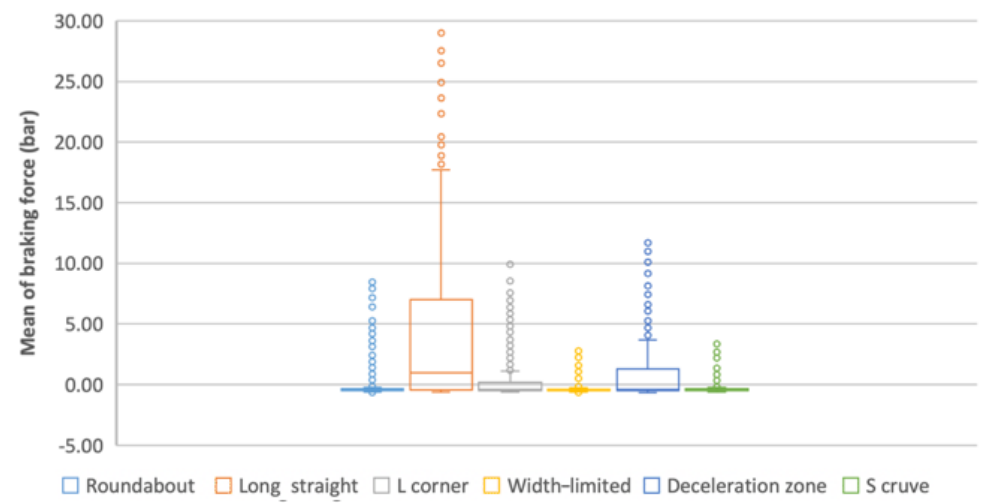

Figure 9. Distribution of M-BF values in different scenes. 
(b) From the radar chart (Figure 4), the M-BF values in other scenes are far away from that in the long straight scene, and the distance of width-limited coincides with that of S-curve, which is in line with the result of (a) and (c).

(c) From the ANOVA (Table 7), there are significant differences in M-BF between other scenes and the long straight scene.

Table 7. Significant comparison results of M-BF in different scenes.

\begin{tabular}{cccc}
\hline \multicolumn{2}{c}{ Driving Scenes } & Mean Difference & Sig. \\
\hline & Roundabout & $4.119^{*}$ & 0.000 \\
L-corner & $3.601 *$ & 0.000 \\
Long straight & Width-limited & $4.344^{*}$ & 0.000 \\
& Deceleration & $3.045^{*}$ & 0.000 \\
& S-curve & $4.242^{*}$ & 0.000 \\
\hline
\end{tabular}

* The mean difference is significant at the 0.05 level.

(d) Summary: M-BF can be used to represent the driving control characteristic in driving scenes including long straight, roundabout, L-corner and deceleration zone.

3.4.6. Standard Deviation of Braking Force

(a) From the box plot (Figure 10), the distribution of SD-BF values is analogous between width-limited and S-curve, while the distribution of others is varied.

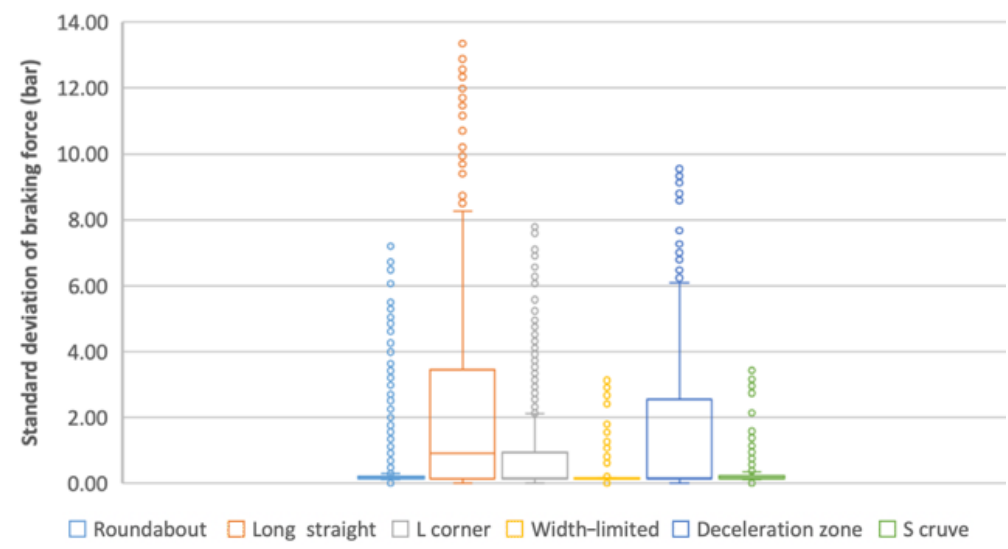

Figure 10. Distribution of SD-BF values in different scenes.

(b) From the radar chart (Figure 4), the SD-BF values in each scene are far from that in the long straight scene, and the distance of width-limited coincides with that of S-curve, which is in line with the results of a) and c).

(c) From the ANOVA (Table 8), significant differences appear in SD-BF between other scenes and the long straight scene.

Table 8. Significant comparing results of SD-BF in different scenes.

\begin{tabular}{|c|c|c|c|}
\hline \multicolumn{2}{|c|}{ Driving Scenes } & \multirow{2}{*}{$\begin{array}{c}\text { Mean Difference } \\
1.820^{*}\end{array}$} & \multirow{2}{*}{$\begin{array}{l}\text { Sig. } \\
0.000\end{array}$} \\
\hline \multirow{5}{*}{ Long straight } & Roundabout & & \\
\hline & L-corner & $1.275 *$ & 0.000 \\
\hline & Width-limited & $2.004 *$ & 0.000 \\
\hline & Deceleration & $0.568 *$ & 0.000 \\
\hline & S-curve & $1.896^{*}$ & 0.000 \\
\hline
\end{tabular}

* The mean difference is significant at the 0.05 level.

(d) Summary: SD-BF can be used to represent the driving control characteristic in driving scenes including long straight, roundabout, L-corner and deceleration zone. 


\subsection{Lateral Parameters}

\subsubsection{Yaw Rate}

(a) From the box plot (Figure 11), the distribution of YR values is analogous between width-limited and deceleration zone, while the distribution of others is varied

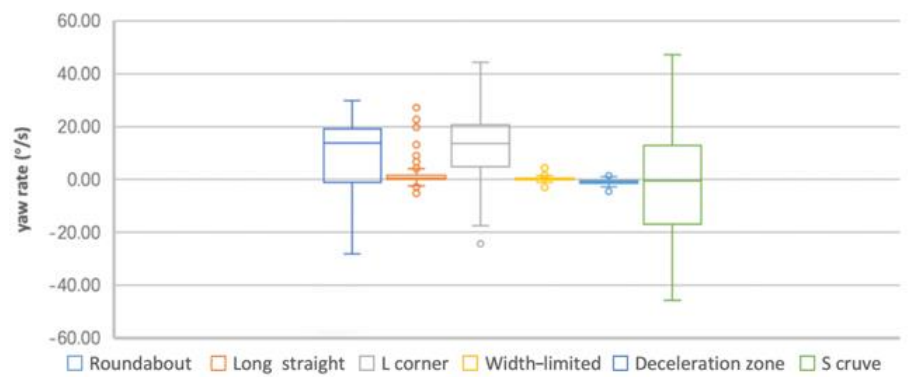

Figure 11. Distribution of YR values in different scenes.

(b) From the radar chart (Figure 4), the YR values in width-limited and deceleration zone are close to center, which means that the difference of YR among long straight, width-limited and deceleration zone is low. This is in line with the results of (a).

(c) From the ANOVA (Table 9), no significant difference appears between long straight, width-limited and deceleration zone.

Table 9. Significant comparison results of $Y R$ in different scenes.

\begin{tabular}{cccc}
\hline \multicolumn{2}{c}{ Driving Scenes } & Mean Difference & Sig. \\
\hline & Roundabout & $\mathbf{- 8 . 2 4 6} \mathbf{*}^{*}$ & $\mathbf{0 . 0 0 0}$ \\
L-corner & $\mathbf{- 1 2 . 3 9 0}$ & $\mathbf{0 . 0 0 0}$ \\
Long straight & Width-limited & 0.677 & 0.290 \\
& Deceleration & 0.583 & 0.106 \\
& S-curve & $\mathbf{1 . 5 3 5 *}$ & $\mathbf{0 . 0 1 9}$ \\
\hline
\end{tabular}

${ }^{*}$ The mean difference is significant at the 0.05 level.

(d) Summary: The YR shows low-level difference in long straight, width-limited and deceleration zone. Therefore, YR can be used to represent the driving control characteristic in driving scenes including S-curve, roundabout and L-corner.

\subsubsection{Mean of Yaw Rate}

(a) From the box plot (Figure 12), the distribution of M-YR values is analogous between width-limited and deceleration zone, while the distribution of others is varied.

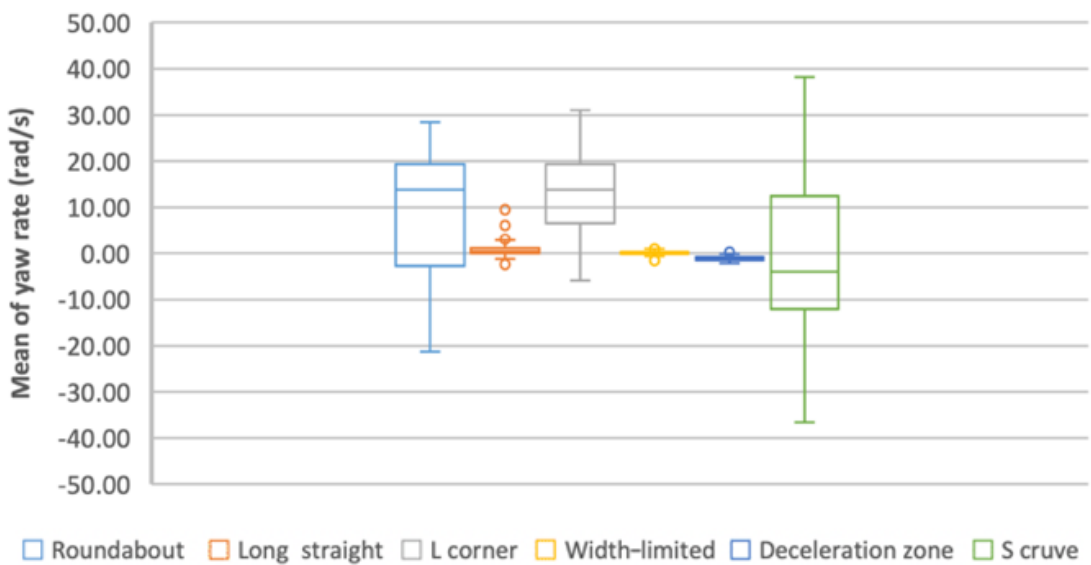

Figure 12. Distribution of M-YR values in different scenes. 
(b) From the radar chart (Figure 4), the M-YR values in width-limited, S-curve and deceleration zone are close to center, which means that the difference of M-YR among long straight, S-curve, width-limited and deceleration zone is low. This is in line with the results of (a).

(c) From the ANOVA (Table 10), no significant difference appears between long straight, width-limited, S-curve and deceleration zone.

Table 10. Significant comparison results of M-YR in different scenes.

\begin{tabular}{|c|c|c|c|}
\hline \multicolumn{2}{|c|}{ Driving Scenes } & \multirow{2}{*}{$\begin{array}{c}\text { Mean Difference } \\
-8.375^{*}\end{array}$} & \multirow{2}{*}{$\begin{array}{l}\text { Sig. } \\
0.000\end{array}$} \\
\hline \multirow{5}{*}{ Long straight } & Roundabout & & \\
\hline & L-corner & $-12.418 *$ & 0.000 \\
\hline & Width-limited & 0.640 & 0.529 \\
\hline & Deceleration & 1.941 & 0.091 \\
\hline & S-curve & 1.487 & 0.150 \\
\hline
\end{tabular}

* The mean difference is significant at the 0.05 level.

(d) Summary: The M-YR shows low-level difference in long straight, width-limited, Scurve and deceleration zone. Therefore, M-YR can be used to represent the driving control characteristic in driving scenes including roundabout and L-corner.

3.5.3. Standard Deviation of Yaw Rate

(a) From the box plot (Figure 13), the distribution of SD-YR values is analogous between width-limited and deceleration zone, while the distribution of others is varied.

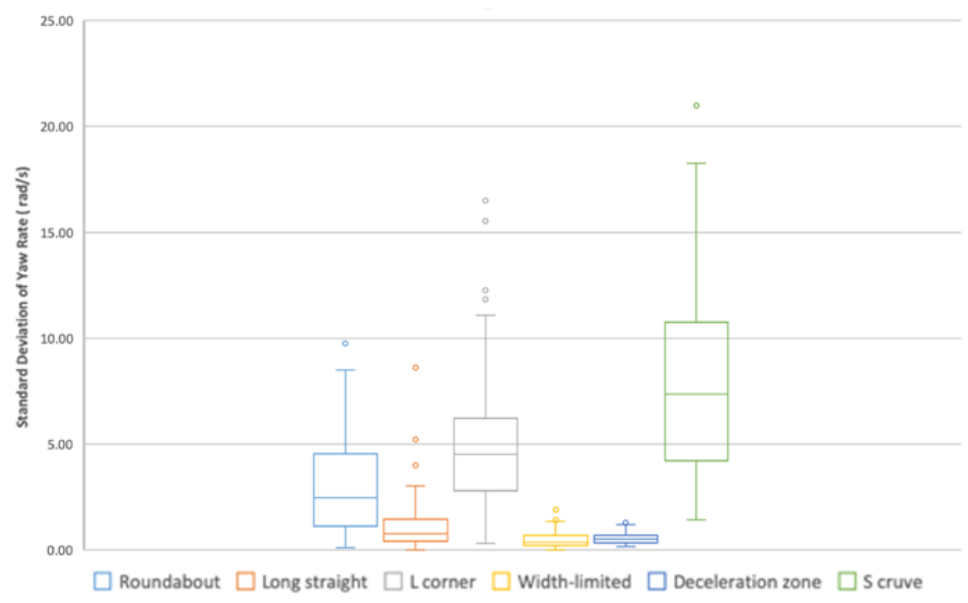

Figure 13. Distribution of SD-YR values in different scenes.

(b) From the radar chart (Figure 4), the M-YR values in all scenes are far from center, which is in line with (c). Moreover, the M-YR value in width-limited coincides with that in deceleration zone, which is in line with (a).

(c) From the ANOVA (Table 11), significant differences appear in SD-YR between other scenes and the long straight scene.

Table 11. Significant comparison results of SD-YR in different scenes.

\begin{tabular}{cccc}
\hline \multicolumn{2}{c}{ Driving Scenes } & Mean Difference & Sig. \\
\hline & Roundabout & $-1.712 *$ & 0.000 \\
L-corner & $-3.602 *$ & 0.000 \\
Long straight & Width-limited & $0.643 *$ & 0.009 \\
& Deceleration & $0.587^{*}$ & 0.036 \\
& S-curve & $-6.847^{*}$ & 0.000 \\
\hline
\end{tabular}

* The mean difference is significant at the 0.05 level. 
(d) Summary: The SD-YR can be used to represent the driving control characteristic in driving scenes including long straight, roundabout, L-corner and S-curve.

\subsubsection{Steering Wheel Angle Velocity}

(a) From the box plot (Figure 14), the distribution of SWV values is analogous between long straight, width-limited and deceleration zone, while the distribution of others is varied.

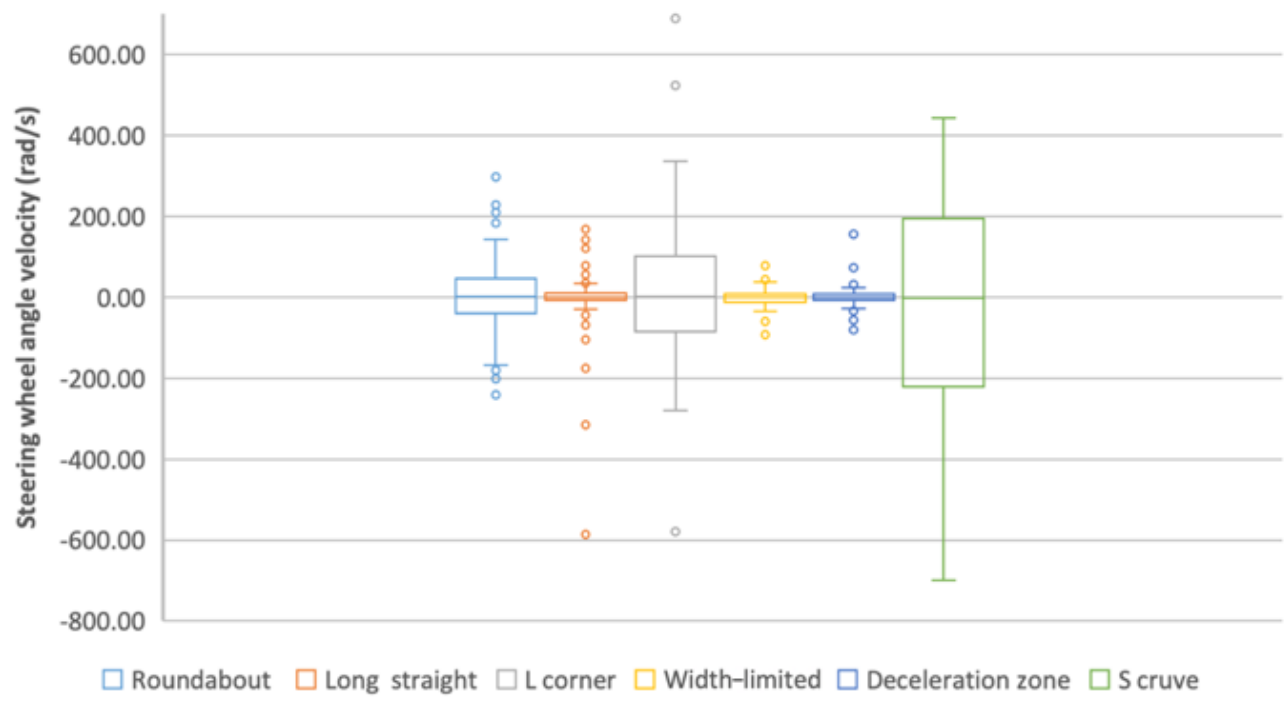

Figure 14. Distribution of SWV values in different scenes.

(b) From the radar chart (Figure 4), the distance among width-limited, deceleration zone and L-corner is small and close to the center of the circle, which is consistent with (a) and (c).

(c) From the ANOVA (Table 12), no significant differences appear between any scenes.

Table 12. Significant comparison results of SWV in different scenes.

\begin{tabular}{|c|c|c|c|}
\hline \multicolumn{2}{|c|}{ Driving Scenes } & Mean Difference & Sig. \\
\hline \multirow{5}{*}{ Long straight } & Roundabout & 1.392 & 0.811 \\
\hline & L-corner & 1.313 & 0.829 \\
\hline & Width-limited & 1.628 & 0.813 \\
\hline & Deceleration & 1.355 & 0.861 \\
\hline & S-curve & 3.405 & 0.621 \\
\hline
\end{tabular}

(d) Summary: The SWV in each scene shows little significance; thus, it cannot be used to represent the driving control characteristic in any driving scenes.

\subsubsection{Mean of Steering Wheel Angle Velocity}

(a) From the box plot (Figure 15), the distribution of M-SWV values is analogous between width-limited and deceleration zone, while the distribution of others is varied.

(b) From the radar chart (Figure 4), the distance among width-limited, deceleration zone and L-corner is small and close to the center of the circle.

(c) From the ANOVA (Table 13), no significant differences appear between any scenes.

(d) Summary: The results of (a), (b) and (c) cannot achieve mutual authentication; the M-SWV is thus not applicable. 


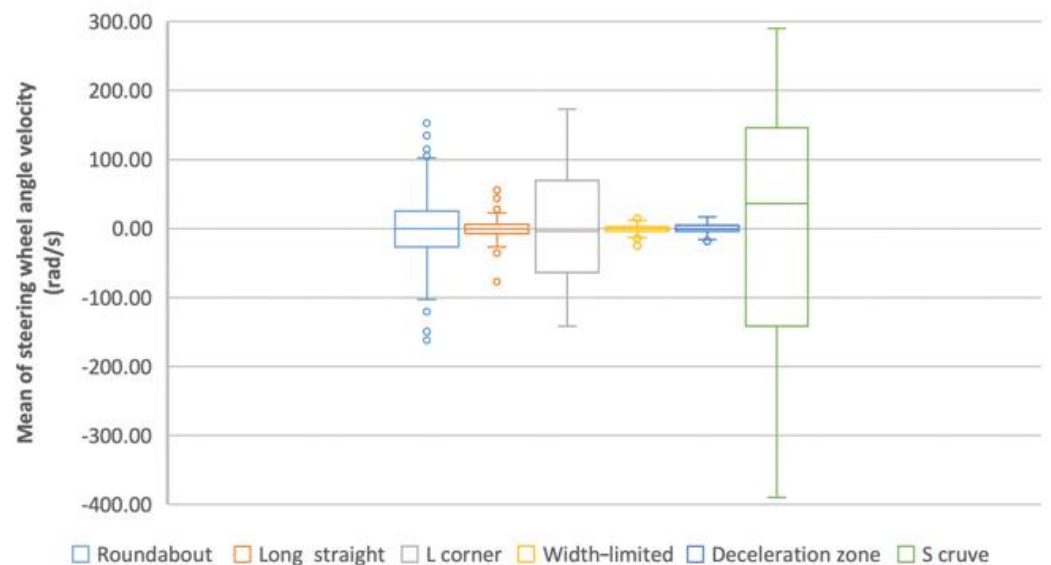

Figure 15. Distribution of M-SWV values in different scenes.

Table 13. Significant comparison results of M-SWV in different scenes.

\begin{tabular}{cccc}
\hline \multicolumn{2}{c}{ Driving Scenes } & Mean Difference & Sig. \\
\hline & Roundabout & 1.133 & 0.853 \\
L-corner & 3.178 & 0.619 \\
Long straight & Width-limited & 0.990 & 0.891 \\
& Deceleration & 0.795 & 0.923 \\
& S-curve & 2.179 & 0.763 \\
\hline
\end{tabular}

\subsubsection{Standard Deviation of Steering Wheel Angle Velocity}

(a) From the box plot (Figure 16), the distribution of SD-SWV values is analogous among long straight, width-limited and deceleration zone, while the distribution of others is varied, which is consistent with (c).

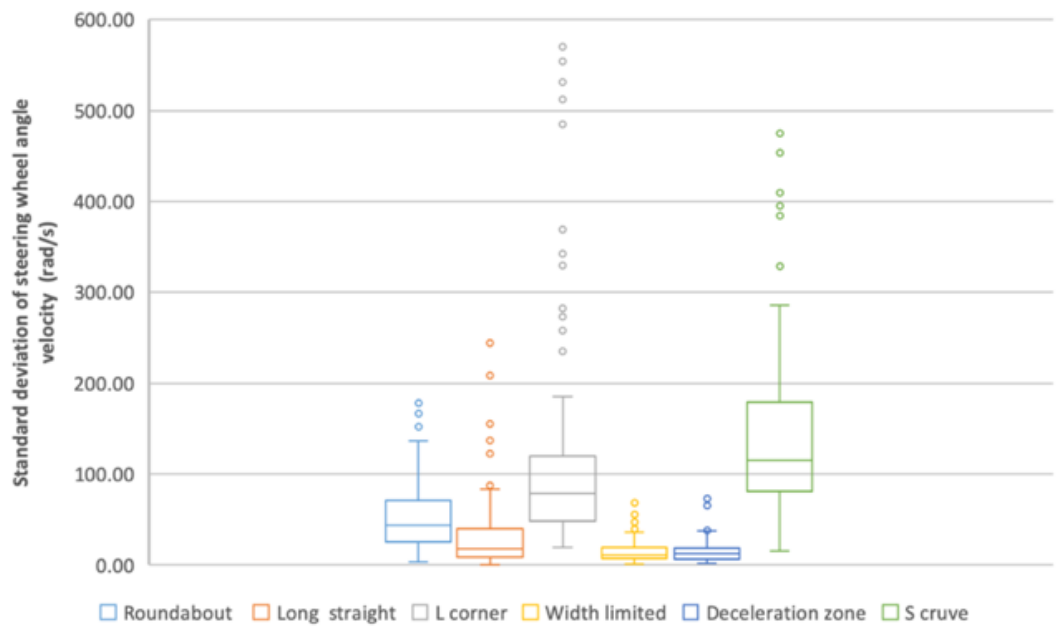

Figure 16. Distribution of SD-SWV values in different scenes.

(b) From the radar chart (Figure 4), the distance between width-limited and deceleration zone is small and close to the center of the circle, which is consistent with (a).

(c) From the ANOVA (Table 14), no significant differences appear between long straight and width-limited, or between long straight and deceleration zone.

(d) Summary: The SD-SWV can be used to represent the driving control characteristic in driving scenes including roundabout, L-corner and S-curve. 
Table 14. Significant comparison results of SD-SWV in different scenes.

\begin{tabular}{|c|c|c|c|}
\hline \multicolumn{2}{|c|}{ Driving Scenes } & Mean Difference & Sig. \\
\hline \multirow{5}{*}{ Long straight } & Roundabout & $-15.239 *$ & 0.006 \\
\hline & L-corner & $-78.603 *$ & 0.000 \\
\hline & Width-limited & 13.879 & 0.053 \\
\hline & Deceleration & 13.534 & 0.070 \\
\hline & S-curve & $-107.334 *$ & 0.000 \\
\hline
\end{tabular}

* The mean difference is significant at the 0.05 level.

\subsubsection{Lateral Acceleration}

(a) From the box plot (Figure 17), the distribution of LAA values is analogous between long straight and width-limited, while the distribution of others is varied, which is consistent with (c).

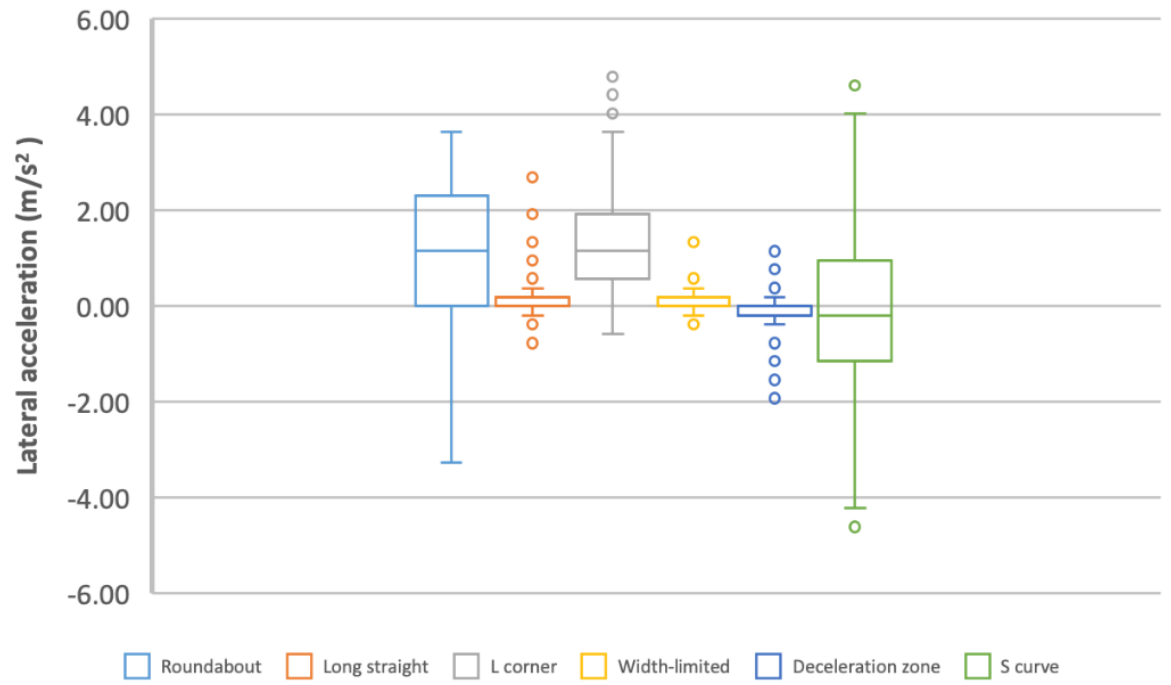

Figure 17. Distribution of LAA values in different scenes.

(b) From the radar chart (Figure 4), the distance between width-limited and deceleration zone is small and close to the center.

(c) From the ANOVA (Table 15), no significant differences appear between long straight and width-limited, or between long straight and deceleration zone.

(d) Summary: The LAA can be used to represent the driving control characteristic in driving scenes including roundabout, L-corner and S-curve.

Table 15. Significant comparison results of LAA in different scenes.

\begin{tabular}{|c|c|c|c|}
\hline \multicolumn{2}{|c|}{ Driving Scenes } & \multirow{2}{*}{$\begin{array}{c}\text { Mean Difference } \\
-0.798^{*}\end{array}$} & \multirow{2}{*}{$\begin{array}{l}\text { Sig. } \\
0.000\end{array}$} \\
\hline \multirow{5}{*}{ Long straight } & Roundabout & & \\
\hline & L-corner & $-1.025 *$ & 0.000 \\
\hline & Width-limited & 0.111 & 0.052 \\
\hline & Deceleration & 0.234 * & 0.000 \\
\hline & S-curve & 0.248 * & 0.000 \\
\hline
\end{tabular}

${ }^{*}$ The mean difference is significant at the 0.05 level.

3.5.8. Mean of Lateral Acceleration

(a) From the box plot (Figure 18), the distribution of M-LAA values is analogous between long straight and width-limited, while the distribution of others is varied, which is consistent with (c). 


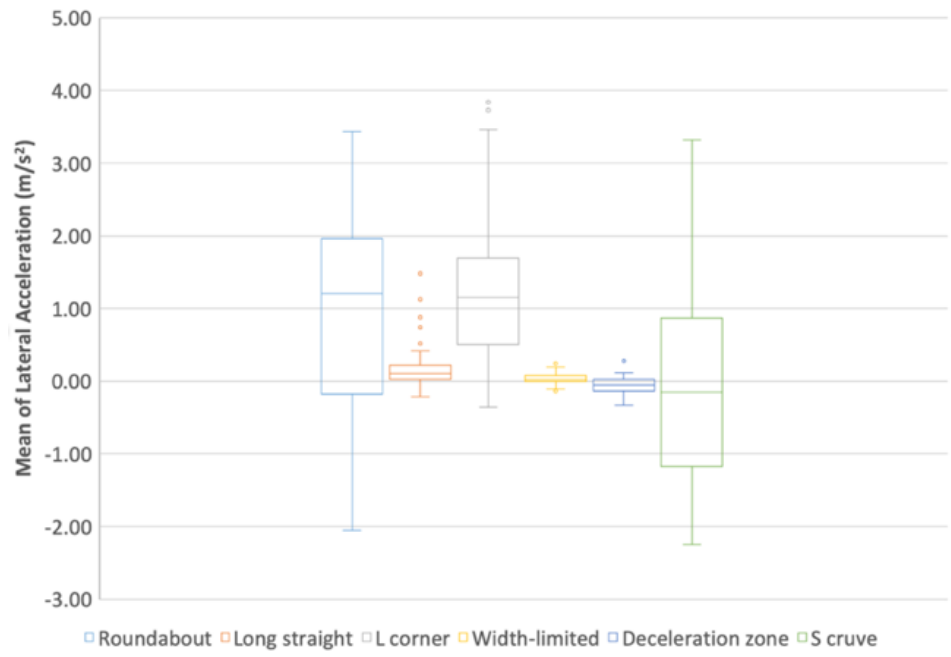

Figure 18. Distribution of M-LAA values in different scenes.

(b) From the radar chart (Figure 4), the distance of width-limited is close to the center, which is consistent with (a)

(c) From the ANOVA (Table 16), no significant differences appear between long straight and width-limited, which is consistent with (b).

(d) Summary: The M-LAA can be used to represent the driving control characteristic in driving scenes including roundabout, L-corner, deceleration zone and S-curve.

Table 16. Significant comparing results of M-LAA in different scenes.

\begin{tabular}{cccc}
\hline \multicolumn{2}{c}{ Driving Scenes } & Mean Difference & Sig. \\
\hline & Roundabout & $-\mathbf{0 . 7 9 1}$ & $\mathbf{0 . 0 0 0}$ \\
L-corner & $-\mathbf{1 . 0 1 6}$ & $\mathbf{0 . 0 0 0}$ \\
Long straight & Width-limited & 0.126 & 0.155 \\
& Deceleration & $\mathbf{0 . 2 5 6}$ & $\mathbf{0 . 0 1 0}$ \\
& S-curve & $\mathbf{0 . 2 6 2}$ & $\mathbf{0 . 0 0 3}$ \\
\hline
\end{tabular}

* The mean difference is significant at the 0.05 level.

\subsubsection{Standard Deviation of Lateral Acceleration}

(a) From the box plot (Figure 19), the distributions of SD-LAA values are different, which is consistent with (c).

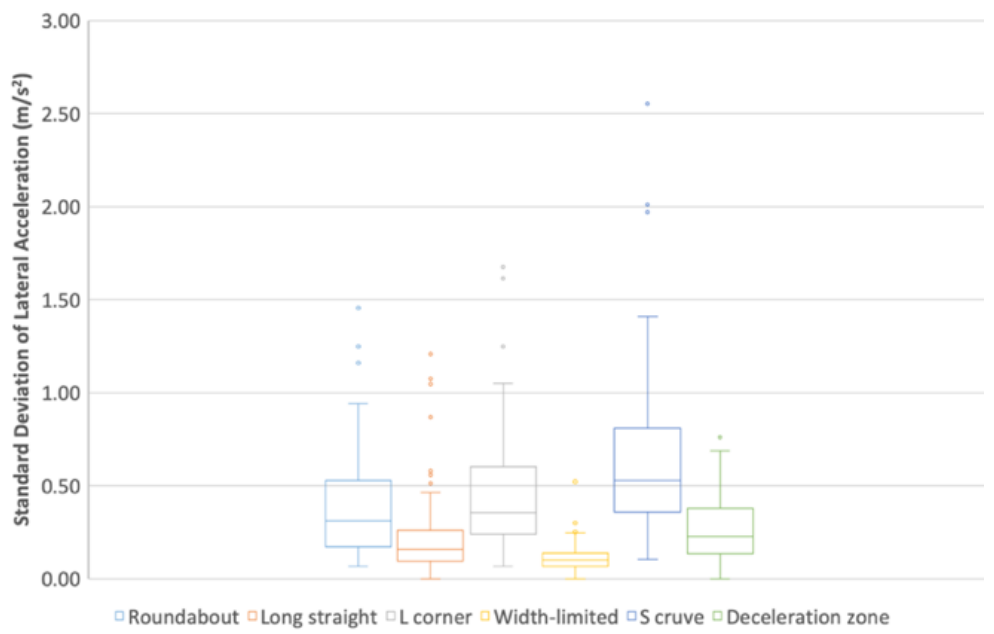

Figure 19. Distribution of SD-LAA values in different scenes. 
(b) From the radar chart (Figure 4), the distances between each index and the long straight scene are different and far from the center, which is consistent with (a).

(c) From the ANOVA (Table 17), significant differences appear between long straight and each index, which is consistent with (a) and (b).

(d) Summary: The SD-LAA can be used to represent the driving control characteristic in all six driving scenes.

Table 17. Significant comparison results of SD-LAA in different scenes.

\begin{tabular}{|c|c|c|c|}
\hline \multicolumn{2}{|c|}{ Driving Scenes } & \multirow{2}{*}{$\begin{array}{c}\text { Mean Difference } \\
-0.138^{*}\end{array}$} & \multirow{2}{*}{$\begin{array}{l}\text { Sig. } \\
0.000\end{array}$} \\
\hline \multirow{5}{*}{ Long straight } & Roundabout & & \\
\hline & L-corner & $-0.213^{*}$ & 0.000 \\
\hline & Width-limited & $0.115 *$ & 0.000 \\
\hline & Deceleration & $-0.057 *$ & 0.050 \\
\hline & S-curve & $-0.404 *$ & 0.000 \\
\hline
\end{tabular}

* The mean difference is significant at the 0.05 level.

\section{Results}

In the present study, six common driving scenes with different points of driving control focus were selected as typical driving scenes. In each scene, we designed corresponding driving tasks and/or interactive behaviors among vehicles. After building a naturalistic driving dataset, a long straight road was chosen as the control variable, and the indicators in other road geometries were compared with it and judged from three perspectives: the overall distribution by box plot, the significant difference test by ANOVA and weight calculation by the entropy method and the relative distance by TOPSIS. Firstly, the box plot was used to observe the change rule and distributional difference of each index. Secondly, taking the control variable as the benchmark and using the entropy weight method to evaluate the weights of the indices, the distance between other scenes' indices and the benchmarks were calculated by TOPSIS. Thirdly, the ANOVA was used to calculate the statistical difference between other indices and the control variables under the $p \leq 0.05$ condition. Consequently, through a triple cross-analysis, the index set that could represent the driving control characteristics in different road types was obtained, as shown in Figure 20. We can draw the following conclusions:

(a) The multi-vehicle interaction behavior in the long straight segment includes passive interference and active driving tasks. The specific driving performance of the road is to avoid the interference of other vehicles or moving obstacles, and to continuously change lanes to overtake them. The driver's lateral and longitudinal vehicle control ability was mainly investigated. The quantitative indices included braking force, longitudinal velocity, lateral acceleration, yaw rate and their derivative variables. The weights of the lateral indices were greater than those of the longitudinal ones, which indicates that the driving task of this segment was more an investigation of lateral driving control ability.

(b) This section mainly focused on lane change and cut-in behaviors in a long curve, and mainly investigated the driver's ability to control the vehicle laterally and longitudinally. The quantitative indices included braking force, lateral acceleration, longitudinal speed, yaw rate, steering wheel angle and their derivative variables. Most of them were transverse indicators, but the weight of longitudinal indicators was large, which shows that these two kinds of indices are essential.

(c) The width-limited segment mainly investigated variable speed car-following in a single lane so as to observe the longitudinal driving control characteristics of drivers. The quantitative indices included longitudinal velocity, lateral acceleration and their derivatives. SD-LAA reflects the change rate of lateral acceleration. Since there was almost no lateral velocity fluctuation in this scene, the SD-LAA was different from that in other scenarios, so that it is the characteristic index of this scene. These two 
kinds of indices can be mapped from the two-dimensional direction of the vehicle to the width-limited scene.

(d) The indices in L-corner and S-curve included steering wheel angle, longitudinal velocity, braking force, yaw rate, lateral acceleration and their derivatives. According to the weight of each index, it can be found that although there was no interference from other vehicles, these two segments have high requirements for the driver's lateral and longitudinal manipulation, and more indices are needed to reflect their characteristics.

(e) The indexes in the deceleration zone segment included longitudinal velocity, braking force, lateral acceleration and their derivatives. It mainly investigated the vehicle driving control state of experienced drivers when passing through a continuous forced-deceleration zone. In addition, the meaning of the lateral acceleration derived index is similar to that of (c).

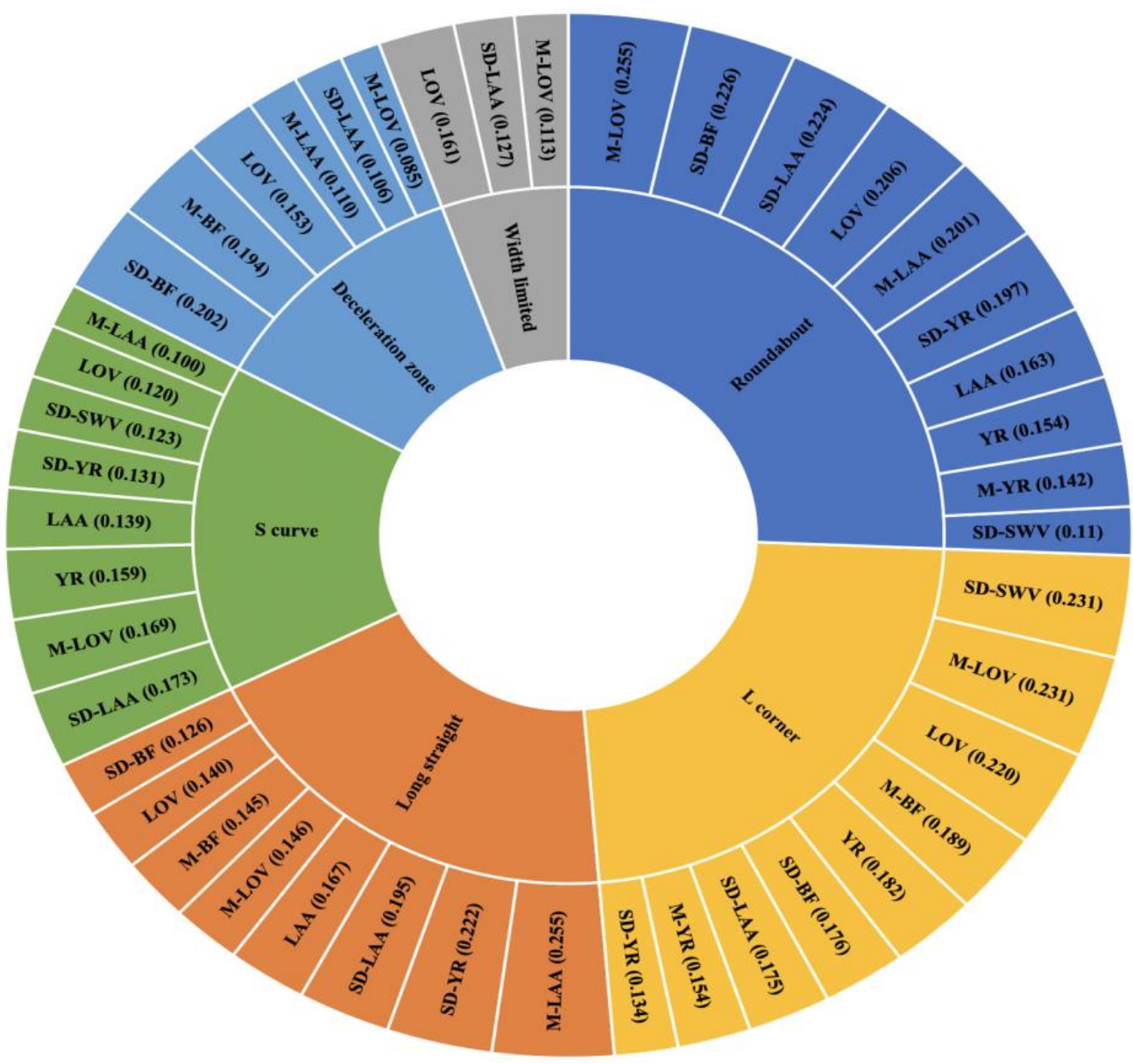

Figure 20. Driving control characteristic evaluation indices and their weights in typical scenes.

After summarizing related publications such as [29-33], we found that no research process or results were identical to those in our study. Among those publications, the horizontal curve was the leading research topic. Speed-related measures have shown a more direct relationship with the radius of the curve than lateral position measures, suggesting that other factors significantly affected drivers' behaviors in the second case. Moreover, they highlighted the current practice regarding driving simulator experiments analyzing road geometry features, which revealed potential sources of bias as well as typical deficiencies in reporting. Suggestions were made for improving the experiments, which can also be useful for other types of driving simulator studies. Therefore, these studies on road geometry are different from our research. 


\section{Summaries and Conclusions}

\subsection{Conclusions}

Summing up the objectives and results from the relevant literature, the main advanced nature of this paper lies in:

(1) The conclusion of this study is based on a real vehicle test. Although there may be some uncertain factors in the actual environment compared with the non-real driving experience of the simulator, our advantage is that we can extract completely real driver control characteristics, which are conducive to completely reflecting the characteristics of driver behavior changes.

(2) Application innovation of method: By strictly comparing the data of drivers' maneuvering performance and road types (data distribution analysis and relative difference calculation, etc.), this cross-analysis method can better determine which indicators in different scenarios have unique rules.

(3) A better explanation of driver-roadway interaction can enhance road design to create a safer traffic system. Moreover, it can also provide basic support for human-like driving or for simulating the driving habits of experienced drivers. This study discusses the handling characteristic indicators of experienced drivers in different driving scenes. Subsequent studies can cite this method or its conclusions to train humanoid driving models so that the models can possess the characteristics of experienced drivers in these scenes.

\subsection{Limitations and Prospects}

There are some limitations in the present study. (a) The site was a closed environment with a speed limitation of $70 \mathrm{~km} / \mathrm{h}$, and the complexity of the road conditions was lower than that of an actual urban road. (b) This study selected six typical road types, which demonstrated a certain reference significance as basic research. In the next step, more and mixed complex road types can be studied to cover more research conditions. (c) A desktop statistical analysis with reported outcomes will show greater significance in practical application in the future research.

In future research based on the conclusion of this paper, we can switch the appropriate indices and use their corresponding weights in different road types, which can provide an accurate analysis effect in many domains, such as for the assessment and prediction of risky driving behavior. Furthermore, it may also help in adjusting the control parameters of automatic vehicles by imitating human drivers' characteristics.

Author Contributions: Conceptualization, B.G. and Q.H.; Data curation, X.X. and H.W.; Formal analysis, B.G.; Funding acquisition, L.J.; Project administration, L.J.; Resources, Z.H.; Validation, B.G.; Writing-original draft, B.G.; Writing-review \& editing, Q.H. and Z.H. All authors have read and agreed to the published version of the manuscript.

Funding: This work is supported by the National Natural Science Foundation of China (52072333, U19A2069), S\&T Program of Hebei (E2020203092).

Institutional Review Board Statement: Not applicable.

Informed Consent Statement: Not applicable.

Data Availability Statement: Data used and analysed during this study are available from the corresponding author by request.

Conflicts of Interest: The authors declare no conflict of interest.

\section{References}

1. National Highway Traffic Safety Administration. Traffic Safety Facts 2011 Data: Rural/Urban Comparison; National Highway Traffic Safety Administration: Washington, DC, USA, 2013.

2. Bobermin, M.P.; Silva, M.M.; Ferreira, S. Driving simulators to evaluate road geometric design effects on driver behaviour: A systematic review. Accid. Anal. Prev. 2020, 150, 105923. [CrossRef] 
3. Wåhlberg, A.A. Speed choice versus celeration behavior as traffic accident predictor. J. Saf. Res. 2006, 37, 43-51. [CrossRef] [PubMed]

4. $\quad$ Simons-Morton, B.G.; Ouimet, M.C.; Zhang, Z.; Klauer, S.; Lee, S.E.; Wang, J.; Albert, P.S.; Dingus, T.A. Crash and Risky Driving Involvement Among Novice Adolescent Drivers and Their Parents. Am. J. Public Health 2011, 101, 2362-2367. [CrossRef]

5. Simons-Morton, B.G.; Cheon, K.; Guo, F.; Albert, P. Trajectories of kinematic risky driving among novice teenagers. Accid. Anal. Prev. 2013, 51, 27-32. [CrossRef]

6. Toledo, T.; Musicant, O.; Lotan, T. In-vehicle data recorders for monitoring and feedback on drivers' behavior. Transp. Res. Part C Emerg. Technol. 2008, 16, 320-331. [CrossRef]

7. Mikolajetz, A.; Henning, M.J.; Tenzer, A.; Zobel, R.; Krems, J.F.; Petzoldt, T. Curve negotiation: Identifying driver behavior around curves with the driver performance database. In Proceedings of the Fifth International Driving Symposium on Human Factors in Driver Assessment, Training and Vehicle Design, Big Sky, MT, USA, 22-25 June 2009.

8. Alsaid, A.; Lee, J.D.; Price, M. Moving into the Loop: An Investigation of Drivers' Steering Behavior in Highly Automated Vehicles. Hum. Factors J. Hum. Factors Ergon. Soc. 2019, 62, 671-683. [CrossRef] [PubMed]

9. Sparrow, A.R.; Lajambe, C.M.; Van Dongen, H.P.A. Drowsiness measures for commercial motor vehicle operations. Accid. Anal. Prev. 2019, 126, 146-159. [CrossRef] [PubMed]

10. $\mathrm{Wu}, \mathrm{K} .-\mathrm{F} . ;$ Jovanis, P.P. Defining and screening crash surrogate events using naturalistic driving data. Accid. Anal. Prev. 2013, 61, 10-22. [CrossRef]

11. Dong, Y.; Hu, Z.; Uchimura, K.; Murayama, N. Driver Inattention Monitoring System for Intelligent Vehicles: A Review. IEEE Trans. Intell. Transp. Syst. 2010, 12, 596-614. [CrossRef]

12. Farahmand, B.; Boroujerdian, A.M. Effect of road geometry on driver fatigue in monotonous environments: A simulator study Transp. Res. Part F Traffic Psychol. Behav. 2018, 58, 640-651. [CrossRef]

13. Guo, B.; Jin, L.; Sun, D.; Shi, J.; Wang, F. Establishment of the characteristic evaluation index system of sec-ondary task driving and analyzing its importance. Transp. Res. F Traffic Psychol. Behav. 2019, 64, 308-317. [CrossRef]

14. Kaur, R.; Sharma, S. Analysis of driver's characteristics on a curved road in a lattice model. Phys. A Stat. Mech. Appl. 2017, 471, 59-67. [CrossRef]

15. Gu, T.; Dolan, J.M. Toward human-like motion planning in urban environments. In Proceedings of the 2014 IEEE Intelligent Vehicles Symposium Proceedings, Dearborn, MI, USA, 8-11 June 2014; pp. 350-355.

16. Kang, X.; Namgung, M.; Fujiwara, A.; Kim, W.; Wang, W. Analysis of Vehicle Maneuverability and Driving Characteristics on a Curved Road Condition. KSCE J. Civ. Eng. 2018, 23, 420-432. [CrossRef]

17. Cerni, G.; Bassani, M. Naturalistic driving data collection to investigate into the effects of road geometrics on track behaviour. Transp. Res. Part C Emerg. Technol. 2017, 77, 1-15. [CrossRef]

18. Wandtner, B.; Schömig, N.; Schmidt, G.J. Secondary task engagement and disengagement in the context of highly automated driving. Transp. Res. F: Traffic Psychol. Behav. 2018, 58, 253-263. [CrossRef]

19. Papadimitriou, E.; Filtness, A.; Theofilatos, A.; Ziakopoulos, A.; Quigley, C.; Yannis, G. Review and ranking of crash risk factors related to the road infrastructure. Accid. Anal. Prev. 2019, 125, 85-97. [CrossRef]

20. Zia, H.; Harris, D.; Smith, D. Infrastructure Risk Rating Manual for Australian Roads No. AP-R587A-19; ARRB: Vermont South, Australia, 2019.

21. Chu, D.; Deng, Z.; He, Y.; Wu, C.; Sun, C.; Lu, Z. Curve speed model for driver assistance based on driving style classification. IET Intell. Transp. Syst. 2017, 11, 501-510. [CrossRef]

22. Carsten, O.; Lai, F.; Barnard, Y.; Jamson, A.H.; Merat, N. Control Task Substitution in Semiautomated Driving: Does It Matter What Aspects Are Automated? Hum. Factors 2012, 54, 747-761. [CrossRef]

23. Zhao, S.-F.; Guo, W.; Zhang, C.-W. Extraction Method of Driver's Mental Component Based on Empirical Mode Decomposition and Approximate Entropy Statistic Characteristic in Vehicle Running State. J. Adv. Transp. 2017, 2017, 9509213. [CrossRef]

24. Hou, M.; Lin, Z.; Chen, J.; Zhai, Y.; Jin, Q.; Zhong, F. Optimization on the Buried Depth of Subsurface Drainage under Greenhouse Condition Based on Entropy Evaluation Method. Entropy 2018, 20, 859. [CrossRef]

25. He, D.; Xu, J.; Chen, X. Information-Theoretic-Entropy Based Weight Aggregation Method in Multiple-Attribute Group DecisionMaking. Entropy 2016, 18, 171. [CrossRef]

26. Ji, Y.; Huang, G.H.; Sun, W. Risk assessment of hydropower stations through an integrated fuzzy entropy-weight multiple criteria decision making method: A case study of the Xiangxi River. Expert Syst. Appl. 2015, 42, 5380-5389. [CrossRef]

27. Jin, L.; Guo, B.; Jiang, Y.; Wang, F.; Xie, X.; Gao, M. Study on the Impact Degrees of Several Driving Behaviors When Driving While Performing Secondary Tasks. IEEE Access 2018, 6, 65772-65782. [CrossRef]

28. Shih, H.-S.; Shyur, H.-J.; Lee, E.S. An extension of TOPSIS for group decision making. Math. Comput. Model. 2007, 45, 801-813. [CrossRef]

29. Calvi, A. A Study on Driving Performance Along Horizontal Curves of Rural Roads. J. Transp. Saf. Secur. 2014, 7, 243-267. [CrossRef]

30. Bobermin, M.P.; Silva, M.M.; Ferreira, S.; Guedes, J.C.C.; Baptista, J.S. Driving simulator for evaluating the effects of road geometric design on driver behavior: Protocol of a systematic review. Int. J. Occup. Environ. Saf. 2019, 3, 46-51. [CrossRef]

31. Choudhari, T.; Maji, A. Assessment of Driver Performance Based on Driver Demography and Road Geometry (No. 18-06523). In Proceedings of the Transportation Research Board 97th Annual Meeting, Washington, DC, USA, 7-11 January 2018. 
32. De Ona, J.; López, G.; Mujalli, R.; Calvo, F.J. Analysis of traffic accidents on rural highways using Latent Class Clustering and Bayesian Networks. Accid. Anal. Prev. 2013, 51, 1-10. [CrossRef] [PubMed]

33. Bella, F. Driver perception hypothesis: Driving simulator study. Transp. Res. F Traffic Psychol. Behav. 2014, 24, 183-196. [CrossRef] 